\title{
22
}

\section{Problems Encountered with the Measurement of Urban Litter entering the Stormwater Systems of Cape Town}

Mark Marais and Neil Armitage

There is a paucity of data on the nature and quantity of urban litter (alternatively called trash or rubbish) that finds its way into the stormwater drainage systems (Armitage et al, 1998; Armitage \& Rooseboom, 2000). This chapter relates how a data collection process was instituted in nine small (34-144 ha) catchments in the City of Cape Town under the Water Research Commission Project No. K5/1051 entitled The reduction of urban litter in drainage systems through integrated catchment management. In keeping with the aim of improving the knowledge of the source, type and amount of urban litter coming from different types of urban catchments, these catchments covered a range of different land uses, socio-economic levels and densities.

The study catchments, the simple devices used to trap the litter, the steps taken to implement the process, including the installation of the trapping devices, and the monitoring procedure are described. The constraints experienced, both in setting up the catchments to enable the collection of the data, and in recording the data are discussed. It is hoped that the lessons learned will prove useful to researchers tackling similar investigations.

Marais, M. and N. Armitage. 2004. "Problems Encountered with the Measurement of Urban Litter entering the Stormwater Systems of Cape Town." Journal of Water Management Modeling R220-22. doi: 10.14796/JWMM.R220-22.

(c) CHI 2004 www.chijournal.org ISSN: 2292-6062 (Formerly in Innovative Modeling of Urban Water Systems. ISBN: 0-9683681-9-0) 


\subsection{Selection of the Study Catchments}

At the commencement of the project, each of the Metropolitan Local Councils (MLCs), into which the current Cape Town City was then divided, identified candidate catchments for inclusion in the study. The project team conducted site visits to the candidate catchments and, together with the MLCs, selected nine catchments that met the project and the then Cape Metropolitan Council (CMC)'s requirements (Figure 22.1). The catchments included:

- Catchment A (Imizamo Yethu) - a low-income, high-density "site and service" residential area where the local authority had provided serviced sites and the residents had erected their own housing structures, generally from scrap materials. As is typical of many such schemes, the inhabited area had grown beyond the boundaries of the serviced sites.

- Catchment B (Ocean View) - a low-income, medium to highdensity residential area comprising of both single dwelling units and hostels (low-income apartments).

- Catchments C, D \& E (Cape Town Central Business District). These catchments in the central business district (CBD) of Cape Town covered a range of activities including a bus depot, informal street traders, the City Hall, shops, offices (including those housing the Receiver of Revenue), hotels, and even a portion of the National Parliament campus.

- Catchment F (Fresnaye) - a high-income, medium-density residential area comprising single dwellingunits and apartment blocks.

- Catchment G (Summer Greens) - a middle-income, mediumdensity residential area.

- Catchment H (Montague Gardens) - a light industrial area.

- Catchment I (Welgemoed) - a high-income, low-density residential area with single dwelling units only.

The CMC approved these sites on 3 March 1999.

The nature and frequency of the domestic rubbish collection services provided by the local authorities varied considerably between the study catchments. Only $52 \%$ of Imizamo Yethu (Catchment A) residents had their refuse removed at least once weekly while $24 \%$ had no refuse removal at all. In contrast at least $97 \%$ of the households in the other residential catchments had their refuse removed at least once weekly. This significantly increased the potential for household refuse to become part of the litter stream in the case of Imizamo Yethu. 


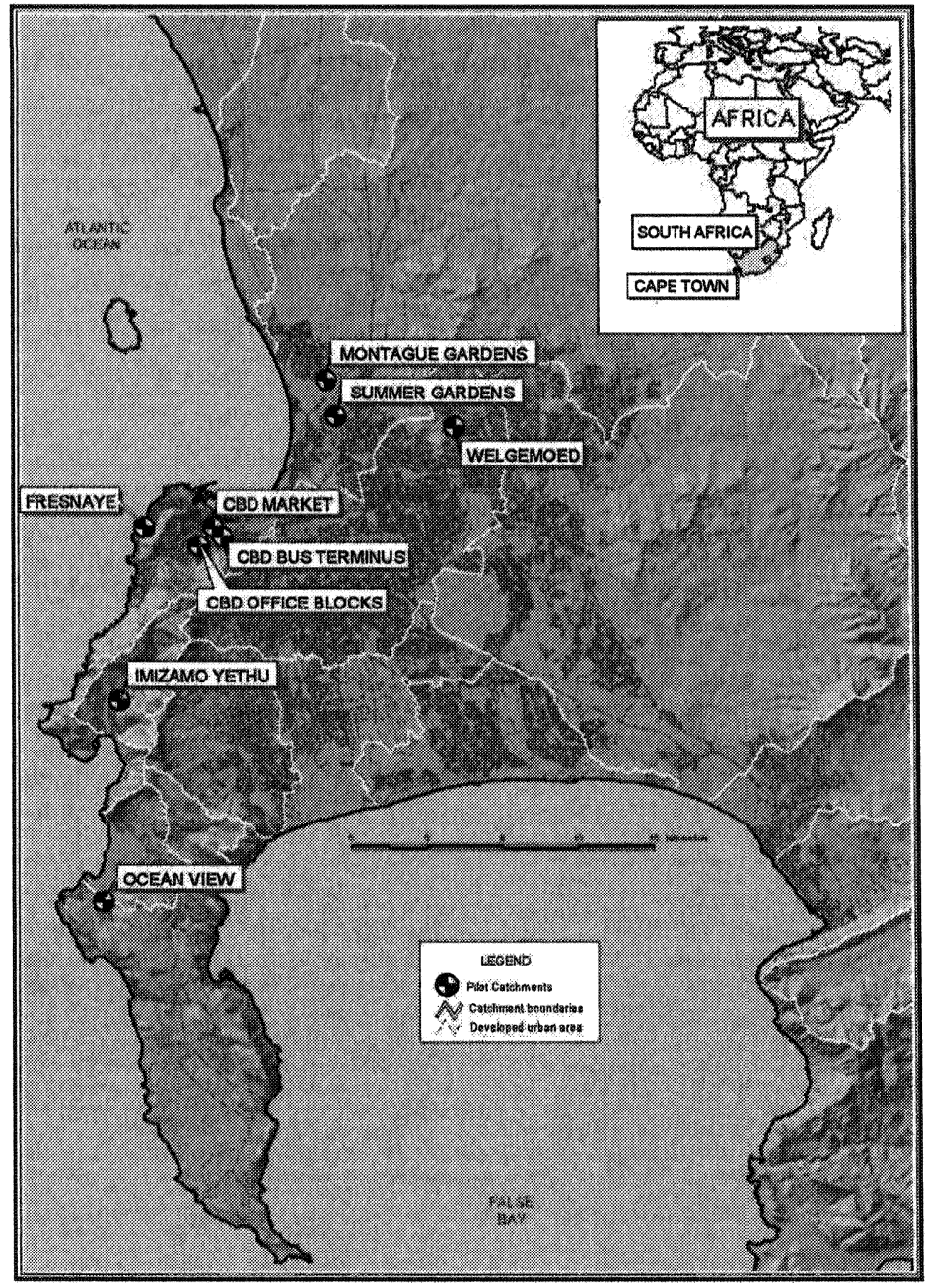

Figure 22.1 Location of the catchments.

\subsection{The Litter Traps}

The catchpits (catchbasins) and stormwater outlets to be fitted with traps were identified from plans supplied by the MLCs and the supply and installation work put out to tender. The tender (bid) process culminated in the appointment of a contractor on 17 August 1999. The costs of manufacturing and installing the traps and nets were borne by the CMC. 
Each catchpit at the side of the road was fitted with a small trap fabricated of galvanised weld mesh with $25 \times 13.4 \mathrm{~mm}$ openings. The mesh was folded on site to suit the catchpit dimensions. A minimum horizontal clearance of 200 $\mathrm{mm}$ between the short sides of the trap and the short walls of the catchpit was generally provided to allow for overflow in the event of the trap becoming blocked. The litter traps were of two different types. They either rested on two horizontal lengths of angle iron bolted to opposing catchpit walls where the configuration of the catchpit allowed, or otherwise they hung from the lip of the catchpit opening below the grid. Ease of fabrication and cheapness were paramount considerations in the design as it was thought the traps might be prone to theft (Figure 22.2).

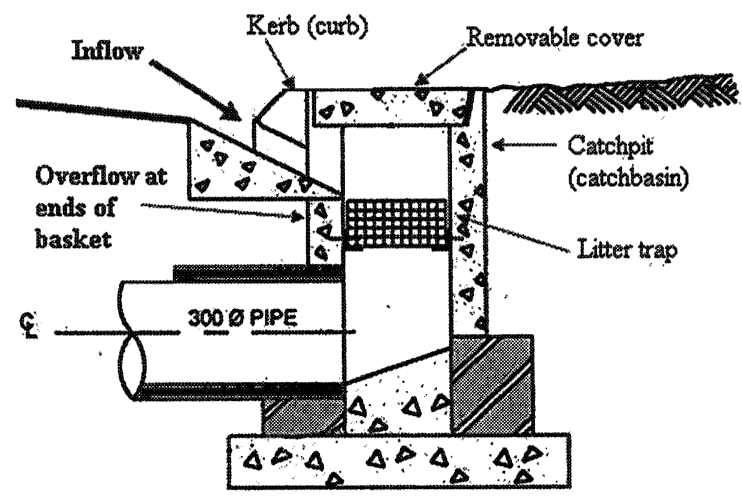

Figure 22.2 Cross-section through a typical side-entry catchpit equipped with litter trap.

The outlets to the catchments were also screened in some manner. The reason for this was to intercept any litter that might bypass the catchpit litter traps. Originally nets made of diamond mesh nylon netting were installed. The end of the net was fastened onto a circular galvanised mild steel hoop fixed to the headwall. A horizontal gap of at least $20 \mathrm{~mm}$ was left between the end of the emerging pipe and the hoop to allow for the passage of water in the event of the net filling with litter (Figure 22.3). In some catchments, the nets were eventually replaced with more robust pressed metal grids.

Each catchpit and outlet net was uniquely identified by a reference number with the format $\mathrm{X} \mathrm{N} \mathrm{N} \mathrm{N} \mathrm{where}$

* $\mathrm{X}=$ catchment code (see Table 22.1)

$* \mathrm{NNN}=$ catchpit or outlet net number. 
CAPE METROPOLTTAN COUNCLL

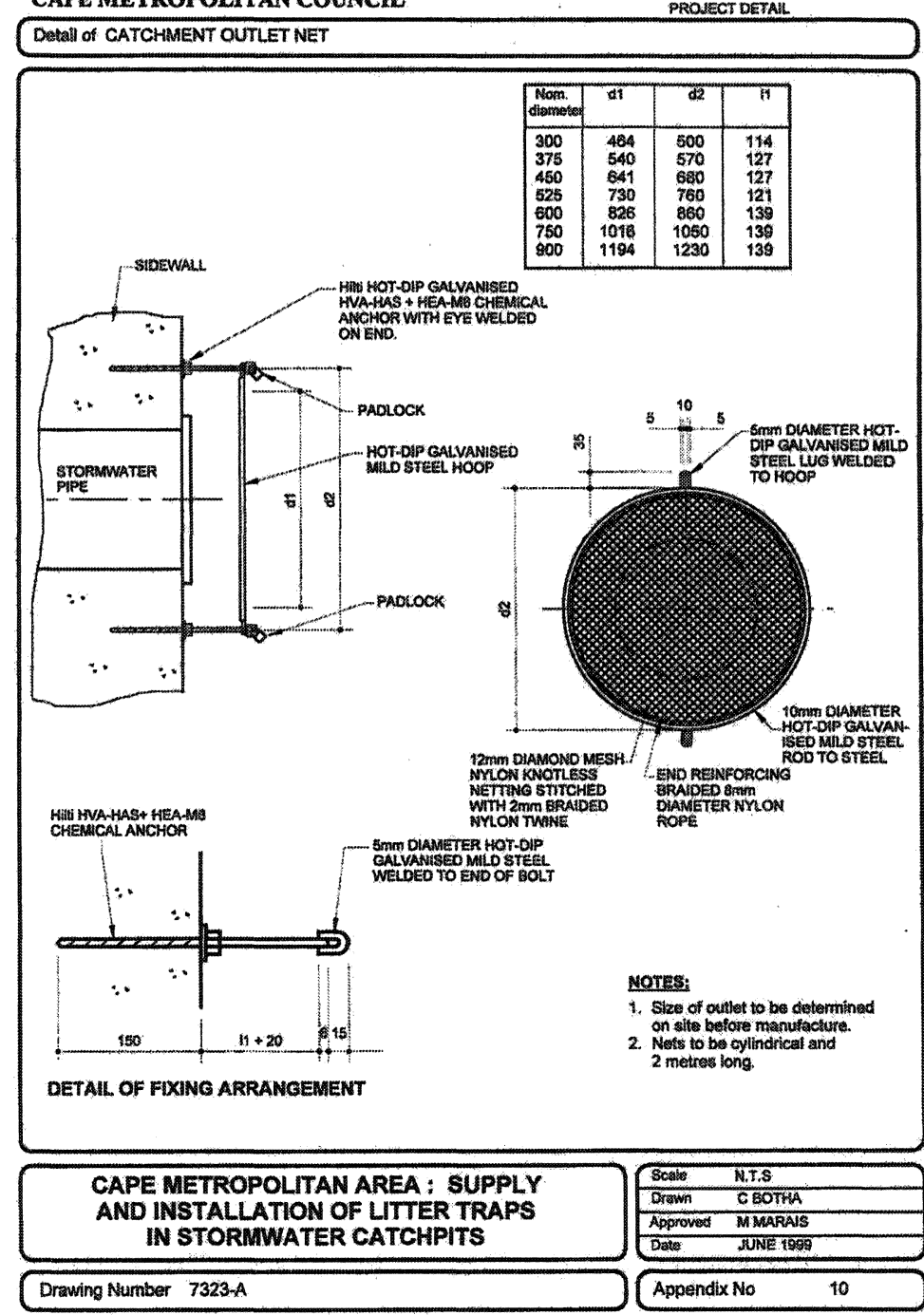

Figure 22.3 Detail of a typical outlet net (as tendered).

The contractor commenced installing the litter traps and catchment outlet nets on 18 August 1999. The Imizamo Yethu, Ocean View, Summer Greens, Montague Gardens and Welgemoed catchments were handed over formonitoring 
Table 22.1 Distribution of catchpits and outlets for selected catchments.

\begin{tabular}{cllrrrr}
\hline $\begin{array}{c}\text { Catchment } \\
\text { Code }\end{array}$ & Suburb & Former MLC & $\begin{array}{c}\text { Area } \\
\left(\mathrm{m}^{2}\right)\end{array}$ & $\begin{array}{c}\text { Side inlet catchpits } \\
(\text { No. })\end{array}$ & $\begin{array}{c}\text { Grid catchpits } \\
(\text { No. })\end{array}$ & $\begin{array}{c}\text { Catchment } \\
\text { Outlets } \\
\text { (No. \& dia.) }\end{array}$ \\
\hline & & & & & & \\
A & Imizamo Yethu & South Peninsula & 53150 & 6 & 15 & $1(525 \phi)$ \\
B & Ocean View & South Peninsula & 115250 & 29 & 5 & $1(450 \phi)$ \\
C & Cape Town CBD & Cape Town & 66000 & 9 & 23 & $1(450 \phi)$ \\
D & Cape Town CBD & Cape Town & & - & 14 & $1(525 \phi)$ \\
E & Cape Town CBD & Cape Town & 34000 & - & 6 & $1(375 \phi)$ \\
F & Fresnaye & Cape Town & 254000 & - & 20 & $1(750 \phi)$ \\
G & Summer Greens & Blaauwberg & 53200 & 8 & 15 & $2(600 \phi, 300 \phi)$ \\
H & Montague Gardens & Blaauwberg & 140685 & 16 & 14 & $1(750 \phi)$ \\
I & Welgemoed & Tygerberg & 144000 & - & 35 & $1(600 \phi)$ \\
ALL & & & 860285 & 68 & 147 & 10 \\
\hline
\end{tabular}


on 26 November 1999 while the CBD catchments were handed over on 3 December 1999. The Fresnaye catchment was handed over much later on 28 February 2000.

The number of stormwater catchpits equipped with traps varied from six (draining the bus terminus in the Cape Town CBD) to 35 (Welgemoed) in each catchment at an average density of 2.5 per ha. Each catchpit was equipped with one or more downstream traps at the outlets to the catchments. In the event of a litter spill from the catchpit litter traps the litter should have been caught in these.

Only the lower portion of Fresnaye was equipped with catchpit traps although the outlet pipe was netted. This meant that those areas of Fresnaye along the main access route and amongst the blocks of flats could be studied in greater detail than the residential areas situated on the steep mountain slopes. This exception was made for reasons of economy in the installation and cleaning of the traps.

The distribution of the catchpit and outlet traps is summarised in Table 22.1.

\subsection{Data Collection}

\subsubsection{Responsibilities of the Local Authorities}

The motivation and methodology of the project were outlined at a workshop with representatives from the then MLCs on 10 February 1999. A follow-up workshop was held with the MLCs on 23 August 1999. The purpose of the latter workshop was to discuss the litter trap monitoring process, the MLC field staff involvement and the financial implications of the project. Workshop attendees were taken to see a trap that had already been installed beforehand in the CBD to observe how the volume of litter was to be recorded.

At that stage it was envisaged that the routine monitoring and clearing of the traps would be conducted by the MLCs' cleansing field staff. Individual workshops in the four affected municipalities, the South Peninsula Municipality, the Cape Town Municipality, the BlaauwbergMunicipality and the Tygerberg Municipality, were held to inform the field staff of the monitoring and recording procedure for the litter traps. It was anticipated that the traps and nets in each catchment would undergo a routine clearout (cleanout) by the local authorities at least once a month. The following data was to be recorded on a standard recording sheet supplied to them: 
- the date of the clearout;

- the duration of the rainfall and precipitation (if any) during the period preceding the clearout;

- the total volume of litter removed from the streets and from the dustbins in the catchment between clearouts; and

- the degree of fullness of each uniquely numbered trap and outlet net.

A detailed analysis was to be undertaken once a month in each catchment during the rainy season (April to September). In addition to recording the above data the contents of each trap and net were to be placed into large plastic bags clearly labelled with the trap/net reference number for sorting and detailed analysis in the University of Cape Town (UCT) Civil Engineering Laboratory.

\subsubsection{Role of the Waste Auditor}

An independent "Waste Auditor" was appointed by UCT for six months fulltime over the winter period April to September of 2000 to carry out the sorting and detailed analysis of the litter. The initial intention was to make a second six month appointment over the same period in 2001. In the course of the six months the Waste Auditor should have been able to carry out about six full analyses of each catchment, at an overall rate of about two per week. For each trap or net the Waste Auditor recorded the exact mass and volume of litter trapped, and indicated the likely source of the litter if known. He also played a vital role in ensuring that trap contents were collected and analysed in an accurate and consistent way.

Altogether, his tasks included:

- Carrying out checks on each catchment in the field to ensure that the local authority teams were properly clearing the catchpits.

- Assisting with the entry of field data on the standard recording sheet. Although this was supposed to be carried out by the MLCs' teams it was found to be essential that the Waste Auditor assist with this function from experience gained in April to September of 2000. Without supervision, the local authority teams did not record the data correctly and tended to assign the same degree of fullness to every trap.

- Working with the local authority team collecting litter for a detailed analysis to ensure that bags were correctly labelled with trap and net numbers before being transported to the UCT Laboratory. 
- Sorting, weighing, and measuring the bag contents and counting the litter items in the Laboratory; recording the results onto standard data sheets; and from the datasheets into the project database (Figure 22.4). The results recorded were the trap contents by type and mass and the likely sources of litter.

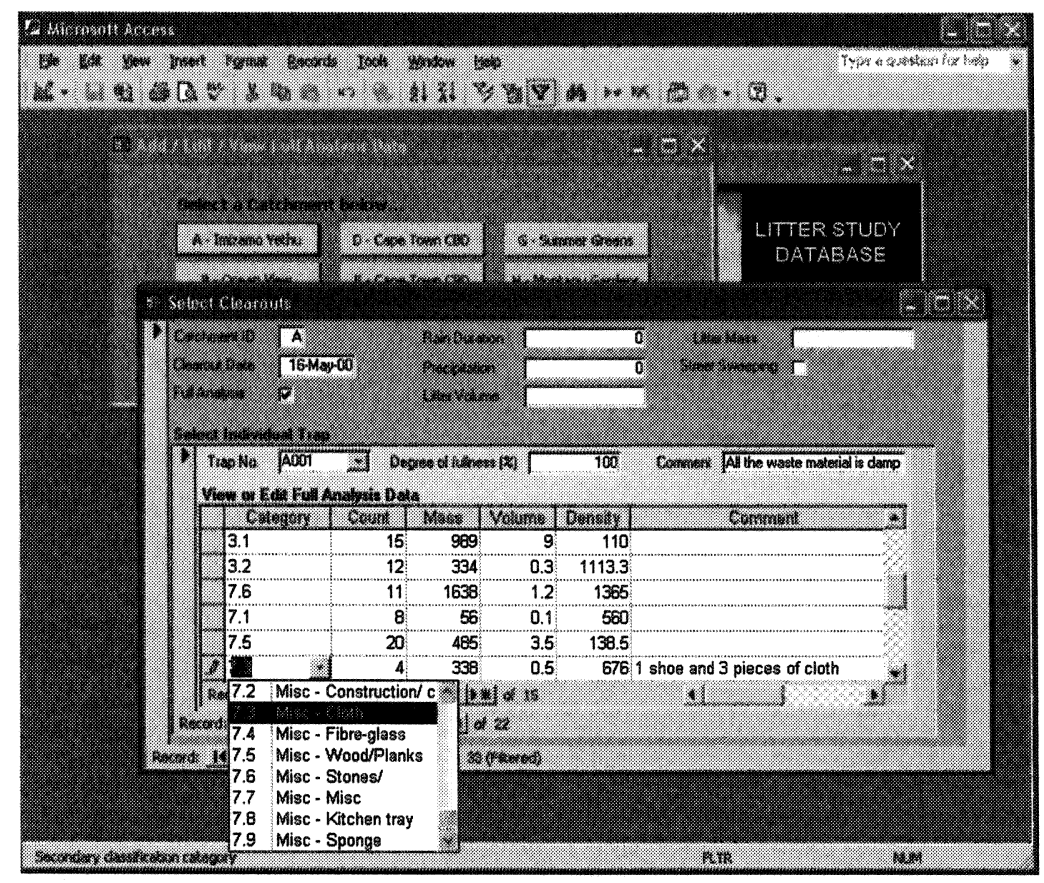

Figure 22.4 Database entry screens.

\subsubsection{Classification of the Litter}

The hierarchical classification system set out in Table 22.2 was employed for recording the litter items. The main categories were selected on the basis of research experience from Armitage et al (1998). The classification system was given flexibility by further subdividing the categories as the study progressed if it was thought important to record the incidence of a specific item. For example plastic chip packets were numerous in Ocean View. Implementing a strategy that targets this one item might significantly reduce the amount of litter emanating from this catchment. This would not have been apparent if the incidence of this specific item was neither monitored nor recorded. 
Table 22.2 Litter classification system.

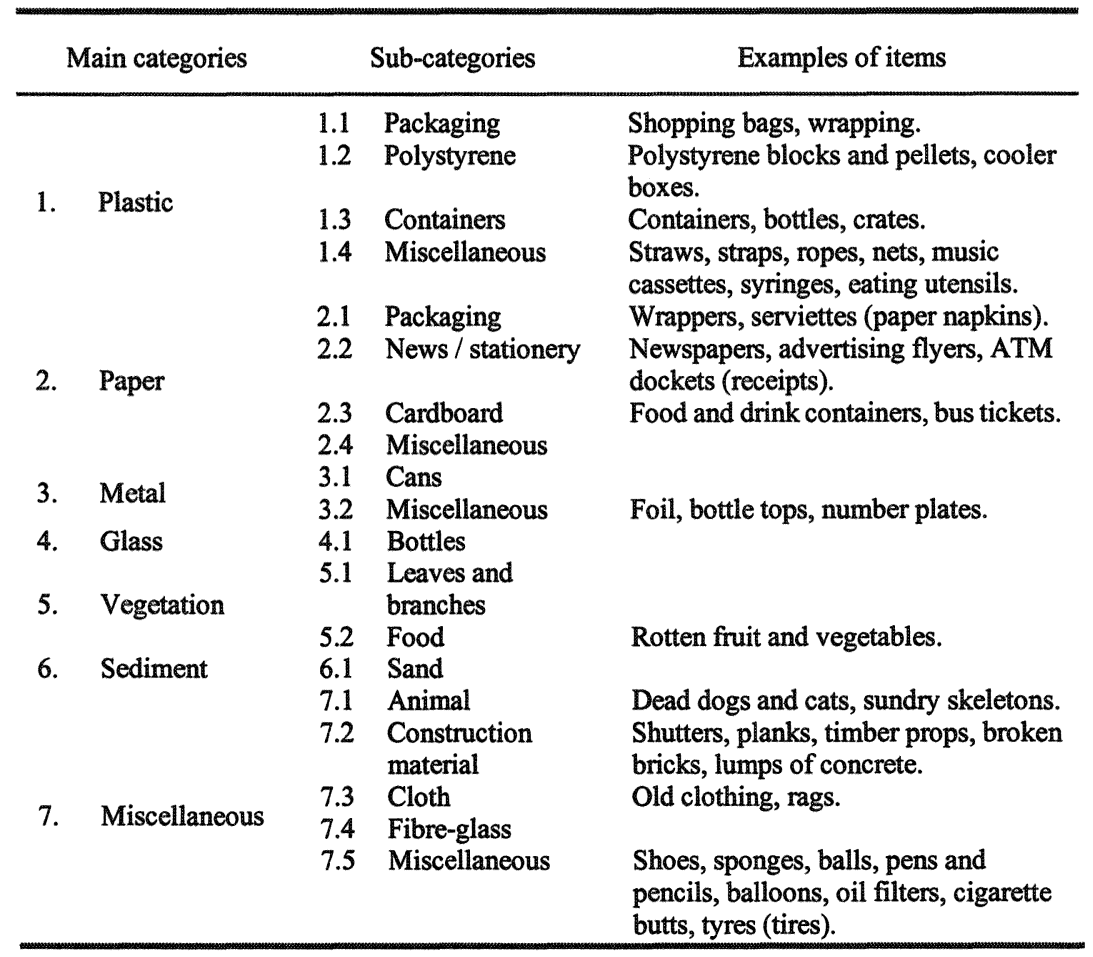

\subsubsection{Adjustments to the Data Collection Procedure}

Experience gained on site over the first monitoring period (January to September 2000) led to a number of changes to the monitoring procedure:

- With notable exceptions it was found that without independent supervision it could not be guaranteed that the data was collected by the local authorities in such a way that its integrity was assured. In particular the degree of fullness recorded was found in many cases to be almost completely arbitrary. As a consequence it was decided to employ the Waste Auditor for the entire twelve-month monitoring period commencing in February 2001 and ending in January 2002 so that he could accompany all collections.

- From October 2000 onwards the local authorities were asked to deliver the litter collected from their routine clearouts in clearly 
labelled bags to the laboratory as for the detailed clearouts so that the total mass of each bag could be determined and recorded for routine clearouts. This was because the local authorities inconsistently recorded the degree of fullness of traps. The volume derived from the degree of fullness of the trap was also found to be an unreliable indicator of mass as the densities of the litter varied so widely, being particularly sensitive to the moisture content. Sorting into different litter categories was not however carried out for these routine clearouts.

- It was also decided to dispense with the counting of litter items in 2001 as this had proved extremely time consuming and, once the litter profile had been established, unnecessary. Litter counts do however give a better indication of the aesthetic impact of lighter materials such as plastic bags and packaging that can appear to be negligible in terms of mass.

- Monthly clearing of the Imizamo Yethu catchment (Catchment A) proved to be inadequate owing to the large mass of silt and litter accumulating in the traps. On one or two occasions, blockage of catchpits had occurred with consequent limited flooding. The frequency of clearing was thus increased to once a week from mid May of 2001. For the same reason the frequency of clearouts in Ocean View was increased to a fortnightly basis from mid May 2001. The frequency of clearouts for the other catchments was maintained at roughly once a month.

\subsection{Problems Encountered and Lessons Learned}

\subsubsection{Implementation}

It took two months from the selection of the pilot catchments to obtain all the stormwater drainage data. It rapidly became evident that much of this drainage data was inaccurate and out of date. In some cases the plans had been drawn up 50 or more years ago and had not been amended when changes had been made. Sometimes two plans of the same area showed different drainage routes. Scales also varied from plan to plan, some maps still being in imperial units. Some of the plans were difficult to read. Although all of the MLCs co-operated with the Project Team in trying to locate accurate information, it was some time before the team could be confident that they had reliable information. 
As the installation of the traps and nets was being funded by the Cape Metropolitan Council the appointment of a Contractor had to pass through their approval process which took a further two months.

The Contractor optimistically tendered a three-week contract period. The actual contract period was close to six months. This extraordinary difference can be attributed to the Contractor underestimating the practical difficulties associated with retrofitting catchpits of differing dimension, scattered over a wide area, and often filled with sand and other debris. This was exacerbated in the case of Imizamo Yethu where night soil (the contents of buckets used in informal latrines) was routinely dumped into the stormwater drainage system.

\subsubsection{Effectiveness of the Traps}

The catchpits were of three basic types; those with side inlets only, those with horizontal grid covered inlets and those with both side inlets and horizontal grid covered inlets. In the case of the latter type the litter baskets were found to trap only a portion of the litter. The items found in the baskets were mostly those that could easily pass through the concrete grid covers (e.g. small paper and plastic wrappings) while the larger items tended to escape the basket. These items were sometimes trapped between the basket and the back of the catchpit underneath the side inlet. This was because the baskets generally did not extend underneath the side inlet opening but were positioned directly below the grid covering. All the litter trapped in the catchpits, both inside and outside the baskets, was however collected and recorded. Based on the quantities trapped in other catchpit types, the data loss was less than $10 \%$. In theory, items that escaped the catchpit litter traps should have been caught in the downstream nets. Some fine material sometimes escaped although not as much as had been originally anticipated owing to the formation of a "filter" consisting of previously trapped material. All anomalous results were recorded in the database.

\subsubsection{The Role of the Local Authorities}

Initially it had been hoped that the four participating MLCs would assist with the collection and volumetric assessment of trap contents. In practice, it was soon realised that this was naïve. Whenever the Waste Auditor did not appear to be watching, the clearing teams rushed through the clearing operation with little regard for the integrity of the data. One local authority team reported every trap to be $50 \%$ full irrespective of how full it actually was. It became clear that 
without independent supervision and some form of reward, the team was unlikely to work carefully. In some instances, special care had to be taken to ensure that the MLC cleansing staff did not think the Waste Auditor was a "spy" evaluating how much of their work could be outsourced to private contractors.

A further problem was interference in the project by other departments of the MLCs concerned. Despite several attempts to keep all interested and affected parties informed of the research project, there frequently seemed to be poor communication within the local authorities, and litter was removed, nets tampered with, and litter management regimes changed without the approval, or even prior notification, of the Project Team.

\subsubsection{Assessing the Fullness of the Traps in the Field}

Initially it had been thought that it was not necessary to conduct a detailed analysis of each and every collection. It was thought that with experience, it would be possible to estimate the average litter load through visual estimates of the fullness of the traps at routine clearings. Detailed analyses, carried out on a lesser frequency, would allow "calibration" of the results of the routine clearings. In estimating the volume of collected litter in the baskets and nets it was initially proposed that degrees of fullness $0,1,2,3,4$ corresponding to $0 \%$, $25 \%, 50 \%, 75 \%$ and $100 \%$ full would be employed for recording in the field.

However this resulted in error and confusion on the part of the local authority teams emptying the baskets. The percentage of fullness (preferably to the closest $10 \%$ ) was then adopted for the recording the volume of collected litter in the baskets and nets. In the end, even this was abandoned, and all the litter was collected and brought back to the UCT lab for weighing and possible detailed analysis.

\subsubsection{Frequency of Collection}

As already mentioned the frequency of clearing in the Imizamo Yethu and Ocean View catchments had to be increased to prevent blockages. Unauthorised and premature clearing of litter in these two in the first phase of the project had led to the loss of important data and disruption of the schedules for clearing. By contrast, in Summer Greens and Welgemoed, the monthly frequency initially adopted had proved to be unnecessarily high. Baskets in these areas were on average found to be less than $10 \%$ full. Regular checking of traps was carried out in order to refine the frequency of collection on an individual basis for each of the pilot catchments. 


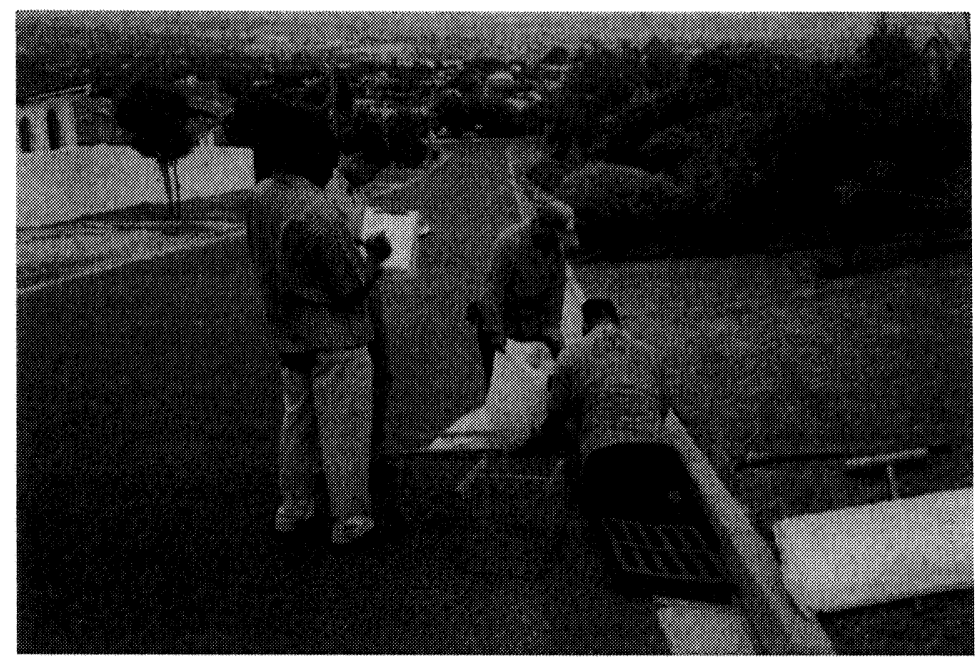

Figure 22.5 Bagging and recording of trap contents in progress in Welgemoed.

\subsubsection{Removal of Traps}

The removal of traps and difficulty in opening catchpits complicated data collection. Sometimes the traps had been stolen, though frequently they were removed by other departments within the MLCs (e.g. the roads department to prevent flooding). During the course of 2001 the missing traps and nets were replaced with the most severely affected areas of Imizamo Yethu and Ocean View enjoying precedence.

\subsubsection{Litter Categories}

Another problem was inherent in the classification and recording of the litter items. Certain litter items have an impact on the environment (even if aesthetic only) which is disproportionate to their mass or volume. Statistically, litter items contributing a small percentage to the litter loading in terms of mass should not be assigned a subcategory. However if there is a high incidence of the items they may merit a separate sub-category. Litter items such as plastic bags have a noticeable and persistent negative impact on the environment even if their contribution by mass is low and were therefore assigned separate subcategories. 


\subsubsection{Method of Measuring}

For each litter subcategory the sorted litter items were weighed on an electronic balance to determine the mass, while the volume was calculated by packing the items into a cubic mould of known base dimensions and measuring the height of the packed items. While it was relatively straightforward to measure the volumes of items such as sand or silt in this way, it was problematic for virtually all other items, such as tin cans, glass bottles, plastic containers and leaves, where the packing arrangement and degree of crushing significantly affected the void ratios and hence the measured volumes and calculated densities.

In addition the processes of collection and bagging in the field and transporting to the laboratory could result in settling of the contents of the bags which were then further disturbed by the sorting operation in the laboratory. As a consequence the laboratory volumes and densities would not necessarily reflect those encountered in the originating drainage system.

As volumes did indeed prove to be too variable, only mass was used in determining and comparing litter profiles. Mass was however influenced by the moisture content. This would have caused some variation because the litter was often wet when bagged, and may have not dried out before measurement.

\subsubsection{Link between Litter Catch and Rainfall}

It was intended that the duration of the rainfall and precipitation (if any) during the period preceding each clearout be recorded on the standard recording sheet. From a comparison of these figures and the amount of litter trapped it was hoped that a link could then be established between litter catch and rainfall. However rainfall measurements did not take place as suitable rain gauges were not established at any of the catchments. The considerable spatial variability of the rainfall throughout the CMA required gauges to be at, or in close proximity to, each catchment to obtain meaningful data.

\subsubsection{Safety and Health Issues}

In the absence of proper services, many households on the periphery of the informal residential settlement of Imizamo Yethu appeared to use the stormwater catchpits as disposal points for night soil and refuse.

Due to the litter containing sharp items, rotting food and even faeces, the Waste Auditor had to be issued with boots, overalls and gloves. The laboratory, where the litter was sorted and measured, had to be sprayed regularly to counter problems with odours and insects. 


\subsubsection{Establishing Baseline Data}

The litter environment within South Africa is rapidly changing. An example of this was the declaration by the Minister of Environmental Affairs that the minimum specification for polyethylene shopping bags was about to be substantially increased that will have an impact on the litter finding its way into the catchpits. The newly consolidated City of Cape Town (CCT) recently introduced a minimum street sweeping service in all the areas under its jurisdiction. Increasingly local authorities, non-governmental organisations (NGOs), and ratepayers are becoming more pro-active in reducing the quantity of litter in the environment. This made it impossible to determine baseline litter data for any particular land-use.

\subsection{Conclusions}

The following conclusions may be drawn from the experience gained in the data collection process:

- The catchment litter situation is rapidly evolving as National Government, the local authority, NGOs and ratepayers each attempt to address the problem. This makes it impossible for anyone to do much more than estimate indicative litter loading figures.

- The data collection process relied on the assistance of the MLCs, which did not have the same objectives or urgency as the Project Team. The MLCs helped greatly with the physical removal of the litter from the traps, bagging the contents and transporting them to the UCT laboratory for analysis, but could not be relied upon to record the litter data. The appointment of a dedicated Waste Auditor to carry out the in-depth analyses of the contents of the litter traps and nets, however, ensured that the contents were analysed in an accurate and consistent way across all nine catchments and proved to be central to the success of the project. Monitoring of the clearing of the litter traps also had to be carried out under the direct supervision of the Waste Auditor to ensure proper collection of the litter.

- The frequency of collections and emptying litter traps and nets should be determined on a catchment by catchment basis as each is unique. This should be reassessed and adjusted during the 
monitoring process as more information about the rate at which the traps and nets fill is obtained. A recommended approach is to adopt a high frequency at the outset which can be reduced as experience is gained.

- Similarly the level of detail of the sampling, recording and classification of litter items should be adjusted as more information about the contents of the traps and nets and the significance of the contribution of specific litter categories or items is obtained. Generally sampling should be as detailed as reasonably possible to begin with and simplified as experience is gained.

- Although the most efficient way to measure litter items and assess their relative contributions is by mass, litter counts should also be undertaken until the litter profile and the average mass per unit for each litter item of interest are established. Thereafter the number of each item in a sample can be estimated from its measured mass. This is of particular importance for those items which have an impact on the environment disproportionate to their mass such as plastic bags.

\section{Acknowledgments}

The information contained in this chapter emanates from a project co-funded by the Water Research Commission of South Africa and the Cape Metropolitan Council Administration of City of Cape Town entitled: "The Removal of Urban Litter in Drainage Systems through Integrated Catchment Management" (WRC Project No. 1051). This is shortly to be published in the form of a report entitled The measurement and reduction of urban litter entering stormwater drainage systems.

\section{References}

Armitage, Neil, Albert Rooseboom, Christo Nel \& Peter Townshend (1998). The Removal of Urban Litter from Stormwater Conduits and Streams. WRC Report No. TT 95/98, Pretoria, ISBN 1868453677.

Armitage, Neil \& Albert Rooseboom (2000). The removal of urban litter from stormwater conduits and streams: Paper 1 - The quantities involved and catchment litter management options. Water SA, Vol. 26, No. 2, pp. 181-187, Pretoria, South Africa. 